\title{
Biomechanical Evidence From Ultrasonography Supports Rigid Foot Orthoses in Children With Flatfoot
}

\author{
Joon-Ho Shin, MD, MS
}

Department of Rehabilitation Medicine, National Rehabilitation Center, Seoul, Korea

Physiologic flatfoot is common and almost asymptomatic and flexible; however, it can be a source of pain, gait pattern change, or scoliosis [1]. The interest in the flatfoot in children has recently increased. Various management options, including medication for pain, orthoses, stretching, footwear selection, activity modification, and surgical management, have been used. Custom foot orthosis is commonly prescribed with the expectation of normal foot and leg function via arch realignment and stability increment; however, the effect is still controversial [2]. A recent study published by Annals of Rehabilitation Medicine demonstrated the clinical improvement in rigid foot orthoses (RFOs) in children with flatfoot [3]. To support the evidence of the effectiveness of RFO, they published new findings as follow-up studies on RFO and the changing muscle properties in this issue of the Annals of Rehabilitation Medicine [4].

The authors [4] investigated changes in the cross-sectional area (CSA) of the ankle invertors and evertors using ultrasonographic measurements and symptoms after 12 months of RFO application in children with symptomatic flatfoot. They explained the clinical effects of RFOs with changes in the CSA ratios of the ankle invertors and evertors and provided an interesting clinical reasoning, wherein PFO reduces the compensatory activities of the ankle invertors, thereby increasing the peroneus longus ratio and reducing pain.

Many biomechanical changes have explained the mechanism of flatfoot, including moment and joint motion changes in the lower extremity $[5,6]$. An imbalance between ankle invertor and evertor has been proposed as another mechanism. Although a previous study failed to reveal the strength of invertors and evertors affects flatfoot, Yalcin et al. [7] revealed that the change in the CSA of the invertor and evertor affects the clinical symptoms for the first time.

For assessment of lower limb biomechanical changes, most studies have used simple radiography and have used computed tomography or magnetic resonance imaging in some cases. Moreover, kinematic or kinetic assessment using a motion capture system, various sensors, or electromyography could provide more detailed information. However, these methods have shortcomings such as radiation-related risks or high cost and require elaborate processes and additional expertise. Therefore, ultrasonography could be a good alternative because it is a safe and painless procedure, especially for flatfoot assessment, which is common in pediatric patients [8].

Received December 13, 2021; Accepted December 20, 2021; Published online December 31, 2021

Corresponding author: Joon-Ho Shin

Department of Rehabilitation Medicine, National Rehabilitation Center, 58 Samgaksan-ro, Gangbuk-gu, Seoul, Korea. Tel: +82-2-901-1884, Fax: +82-2901-1590, E-mail: asfreelyas@gmail.com

ORCID: Joon-Ho Shin (https://orcid.org/0000-0001-6447-8829).

(c) This is an open-access article distributed under the terms of the Creative Commons Attribution Non-Commercial License (http://creativecommons.org/ licenses/by-nc/4.0) which permits unrestricted noncommercial use, distribution, and reproduction in any medium, provided the original work is properly cited. Copyright ( 2021 by Korean Academy of Rehabilitation Medicine 
Based on this study, RFO might be recommended as a standard option for children with symptomatic flatfoot, with clinical and biomechanical evidence from ultrasonography. Moreover, physiatrists can make good use of ultrasonography, thus this type of trial could broaden the research scope in rehabilitation.

\section{CONFLICT OF INTEREST}

No potential conflict of interest relevant to this article was reported.

\section{REFERENCES}

1. Harris EJ, Vanore JV, Thomas JL, Kravitz SR, Mendelson SA, Mendicino RW, et al. Diagnosis and treatment of pediatric flatfoot. J Foot Ankle Surg 2004;43:341-73.

2. Rome K, Ashford RL, Evans A. Non-surgical interventions for paediatric pes planus. Cochrane Database Syst Rev 2010;(7):CD006311.

3. Shin Y, Ahn SY, Bok SK. Relationships between relative ankle muscle ratios, severity of symptoms, and radiologic parameters in adolescent patients with symptomatic flexible flat feet. Ann Rehabil Med 2021;45:123-30.

4. Cho DJ, Ahn SY, Bok SK. Effect of foot orthoses in children with symptomatic flexible flatfoot based on ultrasonography of the ankle invertor and evertor muscles. Ann Rehabil Med 2021;45:459-70.

5. Jafarnezhadgero AA, Shad MM, Majlesi M. Effect of foot orthoses on the medial longitudinal arch in children with flexible flatfoot deformity: a three-dimensional moment analysis. Gait Posture 2017;55:75-80.

6. Han K, Bae K, Levine N, Yang J, Lee JS. Biomechanical effect of foot orthoses on rearfoot motions and joint moment parameters in patients with flexible flatfoot. Med Sci Monit 2019;25:5920-8.

7. Yalcin E, Kurtaran A, Selcuk B, Onder B, Yildirim MO, Akyuz M. Isokinetic measurements of ankle strength and proprioception in patients with flatfoot. Isokinet Exerc Sci 2012;20:167-71.

8. Huang YC, Wang LY, Wang HC, Chang KL, Leong CP. The relationship between the flexible flatfoot and plantar fasciitis: ultrasonographic evaluation. Chang Gung Med J 2004;27:443-8. 